\title{
A PARTILHA SECRETA DO SEGREDO: UMA DISCUSSÃO DE "A CAUSA SECRETA" ATRAVÉS DE SUA FORTUNA CRÍTICA
}

\author{
RAQUEL PARRINE \\ University of Michigan \\ Ann Arbor, Michigan, Estados Unidos
}

Resumo: Em "A causa secreta", Machado de Assis narra a amizade de dois homens, Fortunato e Garcia, marcada por encontros fortuitos e um cenário de adultério e violência. A fortuna crítica em volta do conto desafia a revelação apresentada pelo narrador e mostra horizontes não contemplados pela mente do analista: Paul Dixon ressalta a função do olhar que recai sobre os eventos; Abel Barros Baptista se debruça sobre o papel do analista; Silviano Santiago desconfia das verdadeiras motivações dos encontros fortuitos; Baptista, outra vez, relaciona a arbitrariedade da solução do relato com a arbitrariedade da construção do conto; e Eliane Robert Moraes investiga as conexões entre a prosa machadiana e a do Marquês de Sade. Esse movimento de desconfiança mimetiza a crise do narrador em geral, e a do narrador machadiano em particular, mas também aponta para o segredo da alteridade.

Palavras-chave: Machado de Assis; literatura brasileira; sadismo; segredo

\section{THE SECRET SHARING OF THE SECRET: A DISCUSSION OF "A CAUSA SECRETA" THROUGH ITS CRITICAL RECEPTION}

\begin{abstract}
In "A causa secreta", Machado de Assis narrates the friendship between two men, Fortunato and Garcia, which is marked by random encounters and a scenery of adultery and violence. The literature about this short-story defies the revelation presented by the narrator and showcases horizons not contemplated by the analyst's mind: Paul Dixon highlights the function of the gaze that falls upon the events; Abel Barros Baptista debates issues regarding the role of the analyst; Silviano Santiago is skeptical about the true motivations of the random encounters; Baptista, again, compares the randomness of the tale's solution and the randomness of the construction of the short-story itself; and Eliane Robert Moraes investigates the connections between Machado's prose and that of the Marquis de Sade. This skepticism mimics the narrator's crisis in general and that of the Machadian narrator in particular, while also pointing to the secret of alterity.
\end{abstract}

Keywords: Machado de Assis; Brazilian literature; sadism; secret 
11 causa secreta" saiu originalmente em 1885, no inovador jornal Gazeta de Notícias, fundado em 1875. Foi um dos poucos contos -oriundos dos folhetins que Machado escolheu para serem publicados, posteriormente, em formato livro. Faz parte, assim, de Várias histórias, do ano de 1896.

O conto começa situando os personagens, Garcia, Fortunato e Maria Luiza, em uma cena constrangedora, conversando sobre uma casa de saúde, o dia e um terceiro assunto, "cousa tão feia e grave" que não lhes dava vontade de discutir nada mais. O narrador considera a situação de "tal natureza" que decide recomeçar a contar desde a "origem". ${ }^{1}$

A origem, assim, é o encontro fortuito de Garcia, que era estudante de medicina, e Fortunato, na porta da Santa Casa. Eles não trocam palavras. Alguns dias depois, coincidentemente, se encontram no teatro S. Januário, na rua de D. Manuel, lugar onde, segundo o narrador, "só os mais intrépidos ousavam estender os passos". Nessa sessão, apresentava-se uma peça, "um dramalhão cosido a facadas", a que Fortunato assiste com interesse, entretanto retira-se antes de começar a farsa que o segue. Garcia segue Fortunato pela rua, onde este se detém "para dar uma bengalada" em alguns cães.

Em outra ocasião, Garcia ouve um ferido ser levado pelas escadas, vítima de uma "malta de capoeiras", em estado de saúde grave. Fortunato aparece por acaso, se apresenta como médico e trata o homem, Gouveia. Enquanto Garcia, que auxiliava o médico, está atônito, Fortunato se porta com calma, observando o paciente com atenção e tranquilidade - atitude descrita por Garcia como "um ato de rara dedicação". Depois disso, Fortunato continua visitando o doente, mas, ainda antes que se cure, some sem deixar endereço. Gouveia procura os dados de residência com Garcia e visita a casa de Fortunato, depois de alguns dias, para agradecer sua caridade. O médico, entretanto, trata seu ex-paciente friamente, o que o mortifica e humilha.

Garcia considera o episódio assombroso. O narrador descreve o estudante de medicina como alguém que "poss[ui], em gérmen, a faculdade de decifrar os homens, de decompor os caracteres, $t[\mathrm{em}] \mathrm{o}$ amor da análise, e

\footnotetext{
${ }^{1}$ Todas as citações e referências a "A causa secreta” são de ASSIS, Machado de. Várias histórias. Rio de Janeiro: Garnier, 1900, p. 99-118, com a ortografia atualizada.
} 
sent $[\mathrm{e}]$ o regalo, que di $[\mathrm{z}]$ ser supremo, de penetrar muitas camadas morais, até apalpar o segredo de um organismo".

Garcia e Fortunato voltam a se encontrar aleatoriamente muitas vezes, o que lhes traz familiaridade. Garcia recebe um convite para visitar a casa do médico, agora casado. Já formado, o ex-estudante conhece a esposa de Fortunato, Maria Luiza, e percebe entre os dois uma "dissonância de caracteres": enquanto o marido tinha olhos de "chapas de estanho", a esposa possuía "ambos os feitiços, pessoa e modos".

Em uma de suas visitas ao casal Fortunato, Garcia insiste em contar a Maria Luiza a história de quando os amigos se conheceram. Maria Luiza se sente espantada pelo conto da cura de Gouveia e toca o pulso do marido "como se acabasse de descobrir-lhe o coração". Fortunato, a princípio reticente com a história, a retoma, contando também sobre a visita de Gouveia e, inapropriadamente, ri do episódio. Essa atitude do marido deixa Maria Luiza "desconsolada". Fortunato se refere à dedicação e às habilidades de Garcia como enfermeiro e o convida a abrir uma casa de saúde. Garcia recusa, mas, depois de muita insistência da parte do amigo, aquiesce, para a tristeza de Maria Luiza, que "padecia só com a ideia de que o marido tivesse de viver em contato com enfermidades humanas".

Na casa de saúde, Garcia pode observar melhor o trabalho de Fortunato e se dá conta de que o caso da cura do ferido não era único. Fortunato não se intimida perante nenhuma doença. A proximidade no trabalho traz intimidade entre os dois amigos, e Garcia passa a frequentar a casa do casal Fortunato com muita frequência, chegando a jantar ali quase todos os dias. Começa a observar, também, Maria Luiza, "cuja solidão moral era evidente". Lentamente se apaixona por ela, mas tenta aplacar o sentimento, para que não perturbe a amizade com Fortunato. Maria Luiza, por sua vez, "compreendeu ambas as cousas, a afeição e o silêncio, mas não se deu por achada".

Fortunato se põe a estudar anatomia, "rasg[ando] e envenen[ando] gatos e cães". Os gritos dos animais perturbam os pacientes e, por isso, o médico tem de mudar seu laboratório para sua própria casa, o que aborrece Maria Luiza. Ela resolve recorrer a Garcia e pede-lhe que convença o marido a parar as experiências, o que o amigo logrou fazer. Ao ver que Maria Luiza tossia, Garcia a examina e estabelece que ela precisa de acompanhamento médico.

Dois dias depois (o narrador nos avisa que chegamos ao momento constrangedor do início do texto), Garcia entra no escritório de Fortunato no 
mesmo momento em que Maria Luiza sai de lá em prantos. Testemunha a cena da tortura de um rato feita por Fortunato, que corta as patas do bicho e o aproxima de uma chama, certificando-se, entretanto, de que o animal não morra. Garcia observa o rosto do amigo, que exibe "Nem raiva, nem ódio; tão somente um vasto prazer, quieto e profundo, como daria a outro a audição de uma bela sonata ou a vista de uma estátua divina, alguma cousa parecida com a pura sensação estética". Essa atitude do amigo leva Garcia a concluir que "[a] necessidade de achar uma sensação de prazer, que só a dor alheia lhe pode dar: é o segredo deste homem".

Também se revela, com o tempo, o diagnóstico fatal de Maria Luiza, a tuberculose. Nos seus dias finais, "a índole do marido subjugou qualquer outra afeição". Fortunato "bebeu uma a uma as aflições da bela criatura". Sua atitude era de um "egoísmo aspérrimo, faminto de sensações". Nessas condições, a vida de Maria Luiza expira. Na noite da sua morte, Fortunato acorda e se depara com Garcia, alheio a sua presença, tirando o véu do cadáver e beijando-lhe a testa. Em seguida, arrebenta-se em lágrimas, as quais Fortunato presencia, "sabore[ando] tranquilo essa explosão de dor moral que foi longa, muito longa, deliciosamente longa".

Em 1992, Paul Dixon escreve o primeiro livro inteiramente dedicado à contística machadiana. Analisa dez contos em dez ensaios curtos, entre eles, "A lei dos escravos: 'A causa secreta". O ponto fundamental da análise de Dixon está na observação de que há no conto uma sobreposição de olhares. Assistimos a um padrão, que se inicia no primeiro encontro fortuito entre os dois protagonistas, no teatro: "o de Garcia, observando Fortunato, que por sua vez está a observar algo". ${ }^{2}$ Dixon duvida que este olhar de testemunha seja inteiramente casto. Segundo ele, há algo de paralelo entre esses dois olhares que se detêm sobre o sofrimento alheio. De fato, se Fortunato é um sádico a torturar animais, chutar cachorros na rua e envenenar gatos; Garcia é um "dissecador de almas": 3 a diferença é que o sadismo deste, segundo Dixon, é mais aceito em sociedade. O fascínio de Fortunato ao torturar o rato só seria compatível ao fascínio de Garcia ao observar seu comportamento. Dixon vê o episódio do rato como complemento ao episódio do beijo, em que Fortunato observa Garcia, e não o contrário, e é ele quem se delicia ao olhar o comportamento alheio.

\footnotetext{
${ }^{2}$ DIXON, Os contos de Machado de Assis: mais do que sonha a filosofia, p. 63.

${ }^{3}$ Ibidem.
} 
Para Dixon, este comportamento dos dois personagens poria em cena a questão do estranho de Freud, uma atitude que se repete, que "envolve o leitor num jogo de comparações e contrastes, obrigando-o a colocar em dúvida os limites entre sagradas oposições como sujeito e objeto, normalidade e anomalia, estranho e familiar". 4 Esse é um movimento, segundo o autor, que se poderia localizar em toda a obra de Machado, na medida em que oferece uma dissolução da hierarquia moral em voga na literatura do século XIX, em geral. O leitor não pode ancorar-se no herói para julgar o comportamento dos demais personagens - o conto é um tanque de areia movediça, em que cada movimento do leitor para determinar as personagens só acaba por comprometê-lo. Nesse conto, especificamente, o leitor incauto pode acabar se tornando cúmplice de Garcia, ao aceitar todas as suas soluções e, nesse lance infeliz, enrolar-se numa teia de intenções tenebrosas. Assim, nossas categorias de julgamento são postas em análise, porque "o produto natural do contato entre as pessoas é a cumplicidade". ${ }^{5} \mathrm{~A}$ priori, portanto, participamos das intenções das pessoas antes de rechaçá-las. É assim que, conforme o crítico, as vítimas, uma vez libertas, produzem suas próprias vítimas, como é o caso de Prudêncio de Memórias póstumas, mas também da dinâmica diabólica do conto "Pai contra mãe".

Em "A causa secreta", essa cumplicidade está no olhar encerrado de Fortunato nos olhos de Garcia, apresentado no conto através de um foco narrativo em terceira pessoa, chamado por Dixon de "terceira pessoa limitada". ${ }^{6}$ Essa estratégia sugere ainda, segundo o crítico, mais um par de olhos: os do leitor. Lembre-se que Fortunato tortura o rato com uma sensação que parece "a pura sensação estética", a mesma que assumimos quando observamos uma obra de arte, uma "estátua divina", uma "bela sonata", mas também um conto. Dixon arremata: "A causa secreta de Machado se refere não somente ao sadismo de Fortunato, como também a um segredo ainda mais obscuro - à ideia de que Fortunato tem cúmplices, e que estes existem dentro e fora do mundo fictício do conto". ${ }^{7}$ O crítico implica a todos nós nesse jogo de alianças que o conto fabrica, por meio de sua narrativa. Envolve-nos, leitores, num turbilhão onde as noções de normalidade e perversidade, auxílio e abuso, leitor e personagem se

\footnotetext{
${ }^{4}$ Idem, p. 64.

${ }^{5}$ Idem, p. 66.

${ }^{6}$ Ibidem.

${ }^{7}$ Idem, p. 67.
} 
confundem e são questionadas. "Serão a narrativa e o voyeurismo duplos?", 8 pergunta-nos.

Abel Barros Baptista publicou na revista Espelho, em 1997, o ensaio "Entre o rato e o beijo: analista e segredo em 'A causa secreta"', em que insere uma epígrafe do conto "The Murders in the Rue Morgue". Este conto, de Edgar Allan Poe, também trata da questão da análise e é considerado, historicamente, o primeiro conto policial. A primeira tese de Abel Barros Baptista - e daí a aproximação com esse conto de Poe - é que "A causa secreta" não é a história da natureza íntima de um sádico, mas um conto sobre a análise do gesto analítico.

Baptista critica Dixon quando este afirma um paralelismo entre a cena do rato e a cena do beijo. Para o crítico português, isso sugeriria um paralelismo do segredo. Na primeira cena, Garcia descobre o segredo de Fortunato; na segunda, Fortunato descobre o de Garcia. Entretanto, afirma o narrador de "A causa secreta", este poderia ser "o epílogo de um livro adúltero", mas não é, exatamente porque o segredo de Garcia não é o mesmo segredo de Maria Luiza. Ele a ama, mas não sabe que ela tem conhecimento disso. Então, o segredo descoberto por Fortunato no fim do conto (ou seja, o amor de Garcia por Maria Luiza) não pode contemplar o fato de que existem dois segredos independentes, o que determinaria a diferença entre a afeição e o adultério. Fortunato não pode ver o invisível, a partilha secreta do segredo entre a esposa e o amigo. ${ }^{9}$ E se a visão de Fortunato não pode contemplar toda a verdade dos dois segredos, na cena final, por que não haveria também pontos cegos na visão de Garcia na cena do rato? Na cena do beijo, ocorre algo mais do que a confirmação do segredo de Fortunato. Há uma fratura ambígua na proposição inicial de que este conto seria uma narrativa de decifração, porque

Se a finalidade da narrativa era dizer a verdade sobre Fortunato, a conjunção do recurso ao analista e da "terceira pessoa limitada" vem pôr em causa a possibilidade de a narrativa dizer a verdade sobre Garcia, o qual, entretanto, é o principal fator da possibilidade de dizer a verdade sobre Fortunato! $!^{10}$

\footnotetext{
${ }^{8}$ Ibidem.

${ }^{9}$ BAPTISTA, Entre o rato e o beijo: analista e segredo em "A causa secreta", p. 18-20.

${ }^{10}$ Idem, p. 23.
} 
Essa fratura da autoridade narrativa, de acordo com Baptista, é tematizada pelo conto e está na essência do trabalho do analista. O conto seria, portanto, menos um exercício de decifração do que uma análise desse exercício. Ainda segundo o autor, esse exercício começa pelo momento da descoberta, que não se faz senão de dois movimentos: a ação do acaso que revela o momento único em que o mistério se desfaz, e a consciência que dá testemunho desse momento.

Segundo Baptista, o processo de decifração de Garcia também passa por um momento de conflito de versões sobre a natureza de Fortunato, que o episódio do rato e, depois, o do beijo, irão sanar. O método consistiria em selecionar as pistas e depois avaliar quais dessas características são fortuitas e quais fazem parte da verdadeira natureza de Fortunato. Esse seria o processo de exclusão do segredo. Depois do "momento único", da revelação da "verdadeira natureza" de Fortunato, Garcia dá-se por satisfeito e não considera que haja mais ali para perscrutar.

As conclusões de Garcia, na perspectiva de Baptista, dançam ao sabor do capricho de seu olhar. O crítico assinala que o segredo da causa é esgotado, não porque se chegou à conclusão sobre a natureza de Fortunato, mas porque Garcia perde o interesse nela. Baptista considera que a atividade analítica do médico é uma ilusão, causada pela pressuposição de que sua análise é continuada, quando na verdade ela é por vezes interrompida, postergada, atenuada. Supõe-se que o que Garcia vê é algo que apenas se torna visível, e não fruto de sua atividade de olhar. Um só momento de revelação é capaz de solapar a atividade analítica do conto inteiro, mostrando o poder da crença no olhar, na ilusão de que o que se vê é o que lá está.

O crítico estende a mesma consideração à cena do beijo: os sentimentos de Fortunato servem para confirmar a descoberta de Garcia, mas os sentimentos de Fortunato, contraditoriamente, não estão acessíveis a Garcia, o que faz a confirmação impossível. A mudança do foco narrativo para a consciência de Fortunato, no final, denuncia o fato de que Garcia não pode penetrar sua verdadeira natureza. Portanto, "a arte de Machado consiste em privilegiar a dimensão óptica para denunciar o logro do privilégio da dimensão óptica".11

${ }^{11}$ Idem, p. 32. 
A argumentação de Baptista coincide em muitos pontos com a discussão sobre o segredo desenvolvida por Jacques Derrida em Paixões e "Literature in Secret".

Se o analista, de fato, encontra limites ao seu trabalho de objetivação científica, é bastante normal: ele é a parte interessada do processo que desejaria analisar, pode virtualmente aí desempenhar (quer dizer, também aí arremedar) todos os papéis. Esse limite dá positivamente a condição de sua inteligência; de sua leitura, de suas interpretações. ${ }^{12}$

A análise, segundo Derrida - que também se refere ao detetive de "Murders in the Rue Morgue" -, é uma qualidade pouco passível de análise, só vista através de seus efeitos, que são o divertimento de seu possuidor. Assim, se Garcia, esse analista, encontra dificuldades em sua arte de detecção de caracteres, é porque ele preenche todos os papéis de sua atividade: é o interessado e o verdadeiro ator. Aquilo que não é contemplado por seu gesto interpretativo é o que mostra os seus limites, é o que ressalta a existência de uma consciência gestora do processo. Em outras palavras, se há algo que excede, é aquilo que revela a ilusão da interpretação totalizadora. Ainda segundo Derrida, "Aquilo que tentamos pôr à prova é a possibilidade, na verdade, a impossibilidade de que qualquer testemunho fique seguro de si mesmo, enunciando-se sob esta forma e nesta gramática: "Testemunhemos que..."'. ${ }^{13}$ A condição para essa impossibilidade da segurança do discurso que pretenda dar conta de algo, de testemunhar, seria o segredo. "Há segredo", diz Derrida. Esse segredo de Derrida não tem nome, ou se esconde no nome comum de outros nomes. Não é da dimensão filosófica, religiosa, ou científica.

Heterogêneo em relação ao escondido, ao dissimulável, até mesmo ao não manifesto em geral, ele não é desvendável. Permanece inviolável até quando se acredita tê-lo revelado. Não que se esconda para sempre numa cripta indecifrável, ou atrás de um véu absoluto. Simplesmente excede o jogo do vendar/desvendar: noite/dia, esquecimento/anamnésia, terra/céu etc. Portanto, não pertence à verdade...14

\footnotetext{
${ }^{12}$ DERRIDA, Paixões, p. 41.

${ }^{13}$ Ibidem.

${ }^{14}$ Idem, p. 44.
} 
Não se trata de um segredo como representação dissimulada por um sujeito consciente nem sequer do conteúdo de uma representação inconsciente, algum motivo secreto ou misterioso que o moralista ou o psicanalista teria a arte de detectar, em outras palavras, de des-mistificar. ${ }^{15}$

O segredo não é algo à espera de ser revelado, não é como o inconsciente, que pode escapar, deixar-se antever, ou revelar. O segredo não pode ser confessado, não está guardado. Ele é impossível.

Segundo Derrida, o segredo é o oposto da decifração, mas é também alheio a ela.

De acordo com Derrida, a literatura é o segredo exemplar, descendente do segredo de Abraão, que teve que esconder de todos o pedido de sacrifício de seu próprio filho. Ela pressupõe o direito de dizer/esconder tudo; exime o autor de qualquer responsabilidade em relação à escritura; pode não corresponder, inclusive suspender a realidade; sua única lei é a singularidade da obra artística; forma eventos com vários destinatários e respostas possíveis; possui ao mesmo tempo autonomia e heteronomia em relação ao seu contexto. ${ }^{16}$

Nos termos de Baptista, "há sempre um resto que fica por analisar e que nesse resto se guarda o segredo da narrativa". ${ }^{17}$ Esse "resto" é comparável ao segredo derridiano. É uma dimensão de que o discurso nunca pode dar conta. É uma esfera impenetrável, mas que, ao mesmo tempo, é referida, é apontada. Assim, se o conto tematiza os limites do processo de análise, ele é um conto sobre o segredo - sugerido também no título "A causa secreta". O título aponta para o segredo, mas não o esgota.

Em 2006, Abel Barros Baptista reformula parte da argumentação anterior em um ensaio mais geral sobre a contística de Machado, chamado"A emenda de Sêneca - Machado de Assis e a forma do conto". A emenda de Sêneca é uma teoria retirada de um trecho do conto "O empréstimo", de Papéis avulsos. O conto retoma uma citação de Sêneca: "cada dia é, em si mesmo, uma vida singular", uma "vida dentro da vida", ${ }^{18}$ e a reescreve com um adendo que estabelece que uma só hora também pode conter uma vida inteira. Segundo Baptista, esta seria a diferença entre o conto e o romance:

\footnotetext{
${ }^{15}$ DERRIDA, “Literature in Secret”, p. 42, grifos do autor.

${ }^{16}$ Idem, p. 157.

${ }^{17}$ BAPTISTA, cit., p. 33.

${ }^{18}$ ASSIS apud BAPTISTA, A emenda de Sêneca: Machado de Assis e a forma do conto, p. 212.
} 
"Este narra o percurso de uma vida, enquanto aquele a surpreende representada em trinta ou sessenta minutos" ${ }^{19}$ Eis aí o poder totalizador da revelação, em "A causa secreta", o poder metonímico pressuposto na brevidade do conto, em que um só momento pode dar conta de uma vida, neste caso, o momento da tortura do rato que revela toda a natureza de Fortunato.

Segundo Baptista, "a forma breve supre e ao mesmo tempo mascara a falta de elementos discretos que assinalem o começo e o fim da representação apertada de uma vida inteira". ${ }^{20}$ Isso quer dizer que a forma do conto é absolutamente artificial. Para o crítico, a história breve seleciona e exclui com violência, entre a matéria do caos da existência, aquilo que o narrador deve transformar em sentido, o sentido de uma vida inteira. Deve, inclusive, mascarar a artificialidade dessa ação e apresentá-la como um movimento natural. Assim, a emenda de Sêneca consistiria, justamente, em ver o conto como algo da vida que é sempre exterior a ela. O artista moderno seria aquele que deixa de se pautar na natureza e faz dessa artificialidade seu ofício, na forma de um "simulacro de autorização". ${ }^{21}$

[...] os contos machadianos, parafraseando o filósofo, falam de homens que atuam e representam a ruína da interpretação para dizerem que o sentido da ação humana não é dado, nem ilustrável, nem decifrável, nem transmissível. Não porque seja destituída de sentido, antes porque lhe falta sempre a autoridade do narrador. Mas essa é a razão de ser da emenda de Sêneca. ${ }^{22}$

Assim, para Baptista, a razão de ser da emenda de Sêneca, da ação metonímica do conto, seria provar a artificialidade da voz narrativa e, portanto, que a experiência humana não possui um sentido único, surpreendido nas ações de um personagem. Penso que é o mesmo que o crítico sugere como tema de "A causa secreta", a resistência da natureza humana à interpretação.

A Casa de Rui Barbosa publicou, em 2008, uma edição com cinco contos seguidos de cinco críticas, em uma obra chamada Machado de Assis:

\footnotetext{
${ }^{19}$ BAPTISTA, cit.

${ }^{20}$ BAPTISTA, “A emenda de Sêneca: Machado de Assis e a forma do conto”, p. 214.

${ }^{21}$ Idem, p. 216.

${ }^{22}$ Ibidem.
} 
cinco contos comentados. "A causa secreta" ficou a cargo de Silviano Santiago, e seu ensaio é intitulado "Solidariedade do aborrecimento humano".

Santiago faz uma revisão detida do conto, apontando muitas referências - do romantismo francês ao cinema contemporâneo de Hong Kong. Começa sua análise a partir da estrutura, apontando o início in medias res, na cena do constrangimento dos três protagonistas, entreolhando-se na sala. O segredo e o silêncio desse momento, segundo Santiago, são responsáveis por impulsionar a narração do relato, uma espécie de ativador narrativo. ${ }^{23}$ Essa ordem artificial, que começa pelo meio e depois retorna ao princípio, estaria direcionada para criar o suspense e instigar a curiosidade do narrador e do leitor.

Silviano Santiago, como Paul Dixon, percebe uma cumplicidade entre Garcia e Fortunato, o que ele chama de "empatia de mão dupla" 24 e, mais tarde, de "familiaridade". ${ }^{25} \mathrm{O}$ que há de novo em seu diagrama de cumplicidades é questionar as intenções de Garcia ao perseguir Fortunato.

Haveria motivo profissional para Garcia frequentar a Santa Casa; haveria motivo para Fortunato frequentá-la e, dias mais tarde, haveria motivo para o capitalista caminhar por ruas suspeitas da cidade até deparar com um passante ferido mortalmente por capoeira? Haveria motivo para prestar assistência ao desconhecido? Ou estaria sorvendo até a última gota o prazeroso licor oferecido pelo espetáculo do sofrimento de estranhos? Pouco acaso para muita coincidência. ${ }^{26}$

Santiago observa que, no meio de um inquérito sobre a natureza de Fortunato, passam despercebidas aos olhos do leitor as intenções de Garcia, que frequenta exatamente os mesmos lugares que seu amigo e estaria, assim, suscetível às mesmas suspeitas.

Santiago também indaga o sentido da coincidência desses encontros. Chega a sugerir que Fortunato teria encomendado as facadas desferidas em Gouveia. ${ }^{27} \mathrm{O}$ crítico nos recorda que o especialista em apalpar camadas morais é Fortunato, não Garcia, que é meramente um aprendiz. Inverte-se, assim, o jogo de espionagem, sendo o estudante o observado e o capitalista o perseguidor.

\footnotetext{
${ }^{23}$ SANTIAGO, "Solidariedade do aborrecimento humano", p. 177.

${ }^{24}$ Idem, p. 180.

${ }^{25}$ Idem, p. 181.

${ }^{26}$ Idem, p. 182.

${ }^{27}$ Idem, p. 193.
} 
Silviano Santiago apresenta Garcia como um tipo bizarro de doutor. Ele não estaria, como seria de se supor, interessado nas moléstias do corpo das pessoas, e sim das suas almas. Essa característica seria influência do Roman d'analyse francês. ${ }^{28}$

A tese principal, que dá título ao ensaio, é a da "solidariedade do aborrecimento humano", retirada do capítulo 42 de Memórias póstumas. Santiago lembra-nos do significado que essas palavras tinham no século XIX. Aborrecimento, mais próximo do espanhol aburrimiento, estaria relacionado a tédio, lassidão, ódio, raiva, horror. O conceito, para o crítico, estaria ligado à "comunhão de interesses" dos personagens, que substituiria o aparente acaso de suas relações. De fato, o motor do encontro entre eles estaria menos ligado ao acaso com que a história se apresenta à primeira vista, do que aos interesses particulares e pecuniários de cada um - entre eles, a fundação da casa de saúde. ${ }^{29}$

A solidariedade do aborrecimento humano seria uma espécie de rede de cumplicidades, como a de Paul Dixon, que também engloba o leitor e se transforma em uma solidariedade da leitura. ${ }^{30}$ Parafraseando o conto, Santiago conclui que "A leitura desabrocha no leitor nem raiva, nem ódio, apenas o vasto prazer, quieto e profundo. Os minutos de silêncio subsequentes à leitura levam-no a saborear a explosão de dor moral dos personagens, que é longa, deliciosamente longa". ${ }^{31}$

$\mathrm{O}$ ensaio de Eliane Robert Moraes, "Um vasto prazer, quieto e profundo", de 2009, aborda uma faceta ainda não aprofundada nas análises anteriores: os pormenores do prazer do sádico. Para isso, ela compara o conto com a obra do Marquês de Sade, especialmente Les 120 journées de Sodome.

Para falar sobre o suplício, Moraes convoca Michel Foucault, em Vigiar e punir. A tortura seria não uma consequência de sentimentos, mas uma técnica pormenorizada, que consiste em prorrogar a dor ao máximo possível, a fim de atingir o maior resultado. "O suplício repousa na arte quantitativa do sofrimento." ${ }^{2} \mathrm{O}$ ato é racional, não emocional, e possui uma regulação específica. Assim, para que o suplício aconteça, é necessário não poupar os pormenores. Além disso, é indispensável uma plateia. "Sem cumplicidade

\footnotetext{
${ }^{28}$ Idem, p. 186.

${ }^{29}$ Idem, p. 196-198.

${ }^{30}$ Idem, p. 202-203.

${ }^{31}$ Idem, p. 204.

32 FOUCAULT apud MORAES, Um vasto prazer, quieto e profundo, p. 79.
} 
com o carrasco", afirma a crítica, "não há como tocar o coração do terror." A cumplicidade está entre o narrador e o sádico, ambos dotados de "precisão cirúrgica" ${ }^{33}$

Há em Moraes, como nos outros autores, uma forte desconfiança de que a chave para a causa secreta seja aquela que o narrador está disposto a nos dar. Para a crítica, a explicação não convence porque o conto lança mão de expedientes científicos, que sugerem que a causa secreta não seja uma questão pessoal. O próprio sadismo, afirma, citando Deleuze, é uma subordinação de outros elementos a si. ${ }^{34}$

[...] a causa secreta não pode mesmo se resumir a essa cena [a tortura do rato], nem a qualquer outra, uma vez que ela implica uma ideia pura do Mal - ou, se quisermos, uma negação pura - impossível de conformarse a qualquer particularidade. Neste sentido, Fortunato e Dolmancé são irmãos de sangue e obedecem à mesma lei. ${ }^{35}$

Eliane Moraes evoca Foucault a fim de contar-nos o percurso do sadismo das praças públicas às quatro paredes - entre os séculos XVII e XIX, o que ela chama de "privatização do tormento". Na rua ou em casa, entretanto, o mal surge invariavelmente como dado da condição humana. ${ }^{36}$ Localizamos o rato dentro da privacidade da casa de Fortunato e chamamos sua predisposição de uma causa secreta. Mas fato é que a sua crueldade não é nada particular.

Moraes questiona a ideia, comum a todos os autores que citamos, de que, na última parte do conto, o foco narrativo mude de Garcia para Fortunato. Segundo a crítica, o foco da observação ainda é Fortunato e seus gestos rendem comentários no mesmo teor daqueles feitos pelo discernimento afiado de Garcia - o voyeur das almas humanas ainda está presente, anotando as feições do sádico. Dessa forma, ela desconfia do final edificante do conto e aposta num ocultamento final dos motivos daquele que narra.

Estaria, esse narrador seletivo, ocultando alguma coisa por trás de seu discurso humanitário e edificante? E essa coisa sem nome, grave e feia, não seria justamente a conivência silenciosa do voyeur, a quem cabe

\footnotetext{
33 MORAES, cit.

${ }^{34}$ Ibidem.

${ }^{35}$ Idem, p. 84.

${ }^{36}$ Idem, p. 88.
} 
uma estranha ciência do prazer vasto, quieto e profundo que o algoz experimenta? Não há como sabê-lo. Impossível conhecer a fundo a misteriosa motivação humana para a crueldade. A causa, que viria a explicar a remota origem do mal no coração dos homens, permanece fechada em seu inviolável segredo. ${ }^{37}$

Esse trecho propõe algumas características importantes para o segredo. Ele é, de alguma forma, primeiro indecifrável ("Não há como sabê-lo"), depois "inviolável", na medida em que corresponde à crueldade inerente a todos os homens.

Em todas as leituras recentes de "A causa secreta", como já afirmamos, há uma desconfiança da autoridade de Garcia como solucionador do mistério. Em parte, podemos relacionar esse movimento à crise da legitimidade do narrador contemporâneo de forma geral, e do narrador machadiano em particular, a partir da década de 1960, marcada pela defesa de Capitu feita por Helen Caldwell e discutida extensivamente pela crítica. ${ }^{38}$ Entretanto, a matéria da desconfiança não se encerra completamente na figura do narrador.

$\mathrm{O}$ que todos esses autores apontam, quer questionando o olhar do leitor, quer ressaltando a indecidibilidade da narrativa, é que a solução de Garcia não pode ser a verdadeira natureza de Fortunato. Em parte, porque os seus recursos analíticos estão limitados pela própria razão de ser da análise e, em parte, porque Fortunato está no outro polo da detecção, coberto pelo escuro. Ele está na sombra, alheio ao foco narrativo. Nesse sentido, ele ocupa o lugar da alteridade. O segredo de Fortunato é o segredo do Outro.

$\mathrm{Na}$ obra de Machado, a questão da representação do Outro não é marginal, aparece muitas vezes na forma da mulher, ou do escravo, a cuja consciência não temos acesso. Estamos presos à visão de mundo que o narrador nos traz e, por mais enviesada que ela esteja, é o único registro disponível, performando a tautológica economia do Mesmo. O risco enfrentado todo o tempo pela crítica machadiana é concluir da complexa e ardilosa organização de sua obra - quer sejam os contos, quer sejam os romances - um sentido único e revelador.

A respeito de "A causa secreta", esse equívoco aparece nas afirmações de que teria um sentido claro, ou até uma tese. Donald M. Decker, por exemplo, descreve o conto como parte de um conjunto que exibe certas

${ }^{37}$ Ibidem.

${ }^{38}$ Vide BAPTISTA, O legado de Caldwell ou o paradigma do pé atrás, p. 145-77. 
características em comum: "These are but a few of the stories illustrating clear-cut psychological phenomena or 'cases', as Machado sometimes calls them..." [Estes são apenas alguns contos que ilustram fenômenos psicológicos nítidos, ou "casos", como Machado às vezes os chama]. ${ }^{39}$ Vimos que, ao contrário de "casos" ou elementos nítidos, há muitos temas evocados e camadas invisíveis no entranhado narrativo machadiano. Mas Decker não é o único que simplifica o conto. Como ele, Salvatore D'Onófrio afirma que "[...]o conteúdo significativo se encontra expresso claramente no texto, segundo o costume machadiano...". ${ }^{40}$ Carmelo Virgillo considera a "causa secreta" um traço estrutural da obra de Machado.

[...] true love generally appears in his works as a device concealing an ulterior motive deeply rooted in self-love. This motive Machado himself has called the "causa secreta" or the ugly side of human beings, which his functional characters try to conceal behind a mask of selfless humanity.

[...] o amor verdadeiro geralmente aparece em sua obra como um artifício para ocultar segundas intenções arraigadas profundamente no amor-próprio. Este tema foi chamado pelo próprio Machado como a "causa secreta" ou o lado mau dos seres humanos, que seus personagens funcionais tentam esconder atrás de uma máscara de humanidade abnegada. $^{41}$

Veja-se que a generalização das características da obra machadiana passa por uma didatização de suas características estruturais. A fala conferida ao "próprio Machado" é igual àquela que está em "A causa secreta". Podemos, portanto, notar que há um embuste na estratégia deste conto. Um sentido é declaradamente oferecido, mas aceitá-lo faz aplastar suas sutis camadas de significado.

${ }^{39}$ DECKER, Machado de Assis: Short Story Craftsman, p. 78, minha tradução.

40 D'ONÓFRIO, Tema do sadismo: conto "A causa secreta", p. 34.

${ }^{41}$ VIRGILLO, Love and the "Causa secreta" in the Tales of Machado de Assis, p. 778, minha tradução. 


\section{Referências}

ASSIS, Machado de. Várias histórias. Rio de Janeiro: Garnier, 1900, p. 99-118.

BAPTISTA, Abel Barros. A emenda de Sêneca: Machado de Assis e a forma do conto. Teresa: revista de literatura brasileira, n. 6/7. São Paulo, Ed. 34; Imprensa Oficial, p. 207-231, 2006.

BAPTISTA, Abel Barros. Entre o rato e o beijo: analista e segredo em "A causa secreta". Espelho: Revista Machadiana, n. 3. Porto Alegre, p. 5-35, 1997.

. O legado de Caldwell, ou o paradigma do pé atrás. Santa Barbara Portuguese Studies, n. 1. Santa Bárbara, p. 145-77, 1994.

DECKER, Donald, M. Machado de Assis: Short Story Craftsman. Hispanic World, [s.l.], n. 48, p. 76, 81, 1965.

DERRIDA, Jacques. Literature in Secret. In: The Gift of Death and Literature in Secret. Chicago: University of Chicago Press, 1995.

. Paixões. Campinas: Papirus, 1995.

DIXON, Paul. Os contos de Machado de Assis: mais do que sonha a filosofia. Porto Alegre: Movimento, 1992.

D'ONÓFRIO, Salvatore. Tema do sadismo: conto "A causa secreta". In: D'ONÓFRIO, Salvatore; SILVA, Antonio Manoel dos Santos; MIYAZAKI, Tieko Yamaguchi; CINTRA, Ismael Angelo. (Orgs.). Conto brasileiro, quatro leituras: Machado de Assis, Graciliano Ramos, Guimarães Rosa, Osman Lins. Petrópolis: Vozes, 1979, p. 33-34.

MORAES, Eliane Robert. Um vasto prazer, quieto e profundo. Luso-Brazilian Review, v. 46, p. 75-92, 2009.

SANTIAGO, Silviano. Solidariedade do aborrecimento humano. In: SENNA, Marta de. Machado de Assis: cinco contos comentados. Rio de Janeiro: Edições Casa de Rui Barbosa, 2008, p. 171-205.

VIRGILLO, Carmelo. Love and the "Causa secreta" in the Tales of Machado de Assis. Revista Hispania, vol. 49, n. 4, dez. 1966, p. 778-786.

RAQUEL PARRINE é mestre em teoria literária e literatura comparada pela Universidade de São Paulo e doutoranda em Estudos Hispânicos no Departamento de Romance Languages and Literatures da Universidade de Michigan. E-mail: rparrine@umich.edu.

Recebido: 27.07 .16

Aprovado: 29.09 .16 